\title{
PENGARUH HYPNOBIRTHING TERHADAP LAMA PERSALINAN KALA II PADA IBU BERSALIN PRIMIGRAVIDA
}

\author{
Desy Syswianti' ${ }^{1}$, Tri Wahyuni², Dina Mardiana ${ }^{3}$ \\ 1,2STIKes Karsa Husada Garut \\ 1email: syswianti82desy@gmail.com \\ 2email: tri3wahyuni2014@gmail.com \\ 3Puskesmas Tarogong \\ 3email: dinamardiana80@gmail.com
}

\begin{abstract}
Background: The labor process does not run smoothly if it is not handled properly. Hypnobirthing is an alternative to speed up the labor process. This technique aims to make the mother have a calm spirit with positive energy, which helps relieve pain and anxiety during contractions which have an impact on weakening the uterine contractions and causing the labor process to take a long time. Hypnobirthing can eliminate fear of women during childbirth so that the uterine muscles relax. This will make labor easier and lead to a stress-free delivery.

Purposes: To find out the comparison of the length of the second stage of labor in mothers who apply hypnobirthing and do not apply hypnobirthing, as well as to analyze the effect of hypnobirthing on the duration of the second stage of labor at the Midwife Practice Dina Garut.

Methods: This research is a quasy experiment, with posttest only with control group design. The research was conducted at the Practical Midwife Dina Garut. The sample was selected by purposive sampling, as many as 20 pregnant women for each sample group. Data collection was carried out by observation using the observation sheet for the duration of second stage labor. The data analysis used was the independent sample t test.

Results: The results showed that the average of second stage lenght of labor in the experimental group was 20.24 minutes and the standard deviation was 3.0758. The average of second stage lenght of labor in the control group was 20 - 45 minutes and the standard deviation was 7.3045. Independent sample $t$ test results obtained $t$ of -8.746 and $p$ of $0.000(p<0.05)$, so hypnobirthing affects the length of second stage of labor.

Conclusion: Hypnobirthing influences the length of second stage of labor in primigravida mothers at BPM Midwife Dina Garut.

Suggestion: BPM Dina in particular and in general all midwives in the Garut area, in order to be able to apply to all pregnant women regarding hypnobirthing at an affordable cost, and apply to the entire delivery process
\end{abstract}

Keywords: Hypnobirthing, the length of second stage of labor

\section{ABSTRAK}

Latar Belakang: Proses persalinan tidak berjalan lancar jika tidak ditangani dengan benar. Hypnobirthing menjadi alternatif untuk mempercepat proses persalinan. Teknik ini bertujuan agar ibu memiliki jiwa yang tenang dengan energi positif, yang membantu menghilangkan rasa sakit dan kecemasan selama kontraksi yang berdampak pada melemahnya kontraksi rahim dan menyebabkan proses persalinan berjalan lama. Hypnobirthing dapat menghilangkan rasa takut pada wanita saat melahirkan sehingga otot rahim menjadi relaksasi. Hal ini akan mempermudah proses persalinan dan menyebabkan persalinan yang bebas stres.

Tujuan: Untuk mengetahui perbandingan lama persalinan kala II pada ibu yang menerapkan hypnobirthing dan tidak menerapkan hypnobirthing, serta menganalisis pengaruh hypnobirthing terhadap lama persalinan kala II di Bidan Praktik Dina Garut.

Metode: Penelitian ini merupakan quasy eksperimen, dengan posttest only with control group design. Penelitian dilakukan di Bidan Praktik Dina Garut. Sampel dipilih dengan purposive sampling, sebanyak 20 wanita hamil untuk setiap kelompok sampel. Pengumpulan data dilakukan secara observasi dengan menggunakan lembar observasi lama persalinan kala II. Analisis data yang digunakan adalah uji t sampel independen.

Hasil: Hasil penelitian menunjukkan bahwa rata-rata lama persalinan kala II pada kelompok eksperimen adalah 20,24 menit dan standar deviasi adalah 3,0758. Rata-rata lama persalinan kala II pada kelompok kontrol adalah 20 - 45 menit dan standar deviasi adalah 7,3045. Hasil uji t sampel independen diperoleh t sebesar -8,746 dan $p$ sebesar $0,000(p<0,05)$, sehingga hypnobirthing berpengaruh terhadap lama persalinan kala II. 
Kesimpulan: Hypnobirthing berpengaruh terhadap lama persalinan kala II pada ibu primigravida di BPM Bidan Dina Garut.

Saran Bidan Praktik Dina khususnya dan secara umum seluruh bidan yang ada di wilayah Garut, agar dapat menerapkan kepada seluruh ibu hamil mengenai hypnobirthing dengan biaya yang terjangkau, dan menerapkan pada seluruh proses persalinan

Kata Kunci: Hypnobirthing, Lama Persalinan Kala II

\section{PENDAHULUAN}

Salah satu kodrat perempuan adalah melahirkan anak, di mana dalam prosesnya ibu melahirkan akan merasakan sakit. Proses persalinan yang berjalan normal dan tanpa adanya komplikasi menjadi sebuah pengalaman positif sekaligus memuaskan bagi ibu melahirkan. Komplikasi yang terjadi selama persalinan menjadi salah satu penyebab kematian ibu melahirkan. Berdasarkan hasil penelitian diperoleh bahwa kejadian komplikasi persalinan prosentasenya yang terbesar adalah persalinan lama, selanjutnya perdarahan dan preeklamsia (Widiawati, 2019).

Menurut Mochtar (Wildan, Jamhariyah, \& Purwaningrum, 2013) proses persalinan meliputi 4 kala, di mana kala I adalah waktu pembukaan serviks $1-10 \mathrm{~cm}$. Kala II adalah waktu dikeluarkannya janin. Kalau II merupakan kala dilepaskan dan dikeluarkannya uri. Adapun kala IV digunakan untuk observasi post partum pada 2 jam pertama.

Persalinan Kala II terjadi setelah pembukaan lengkap $(10 \mathrm{~cm})$ sampai bayi lahir. Pada fase aktif ibu mengejan, keseluruhan tempo aktivitas akan berubah, aktivitas uterus mengalami perubahan dan hal ini menyebabkan respon ibu pada persalinan sering kali berubah dari konfulsi dan kehilangan kontrol menjadi aktivitas mengejan yang kuat sampai bayi lahir. Hal ini disamping diperlukan stamina dan keberanian ibu, juga keyakinan terhadap keterampilan bidan yang membantu proses kelahiran (Rini, 2010).

Proses persalinan apabila tidak ditangani secara baik menyebabkan proses persalinan tidak lancar, dan menyebabkan persalinan yang lama (Astuti \& Noviyanti, 2015). Respon stres menjadi faktor yang menempati urutan paling atas sebagai salah satu faktor penyebab persalinan lama (Wildan, Jamhariyah, \& Purwaningrum, 2013). Stres pada ibu melahirkan berdampak pada melemahnya kontraksi rahim dan menyebabkan proses persalinan berjalan lama, bahkan berpotensi menyebabkan kematian ibu melahirkan (Prawirohardjo, 2010).

Hypnobirthing menjadi sebuah alternatif untuk mempercepat proses persalinan. Teknik ini merupakan alternatif alami agar ibu hamil mempunyai jiwa yang lebih tenang dengan energi positif, yang dapat membantu untuk meringankan rasa sakit dan kecemasan saat mengalami kontraksi, sehingga mempercepat proses persalinan (Syahda \& Ramaida, 2017). Hypnobirthing mengekspolarasi mitos yang menyatakan bahwa adalah wajar apabila persalinan merasakan sakit, dan pada saat persalinan normal, hal ini dibutuhkan. Apabila rasa takut pada wanita saat melahirkan dapat dihilangkan, maka akan terjadi relaksasi pada otot tubuhnya termasuk otot rahim. Hal ini akan mempermudah proses persalinan dan menyebabkan persalinan yang bebas stres (Sariati, Windari, \& Hastuti, 2016). Hypnobirthing dapat memberikan sugesti bahwa proses persalinan itu nikmat (Devi, Sulastriningsih, \& Tiawaningrum, 2018).

Tujuan dari metode ini adalah mencegah terjadi proses persalinan yang lama karena faktor psikologis ibu yaitu perasaan takut dan cemas dalam menghadapi persalinan. Pada hypnobirthing, digunakan teknik relaksasi mendalam, pola pernafasan lambat dan petunjuk cara melepaskan endorfin dari dalam tubuh (relaksan alami tubuh), sehingga hal ini memungkinkan ibu melahirkan menikmati proses persalinan yang aman, lembut, cepat dan tanpa proses pembedahan (Rini 2010).

Berbagai penelitian terdahulu yang dilakukan telah membuktikan bahwa penerapan metode hypnobirthing berpengaruh untuk mempercepat persalinan pada kala I (Widiawati, 2019); (Devi, Sulastriningsih, \& Tiawaningrum, 2018); (Karuniawati \& Fauziandari, 2017); (Nuryanti, Nisman, \& Siswosudarmo, 2017); (Astuti \& Noviyanti, 2015). Sebuah penelitian terdahulu juga membuktikan bahwa penerapan metode hypnobirthing berpengaruh untuk mempercepat persalinan pada kala II (Rini 2010).

Penerapan hypnobirthing telah dilakukan kepada ibu hamil yang memeriksakan diri di BPM Bidan Dina Garut. Penerapan hypnobirthing dilakukan di luar jam periksa, dan ibu hamil harus membayar biaya hypnobirthing tersebut. Hal ini menyebabkan tidak semua ibu hamil dapat mengikuti hypnobirthing yang diselenggarakan di BPN tersebut.

Tujuan dari penelitian ini adalah untuk mengetahui lama persalinan kala II pada ibu yang 
tidak menerapkan hypnobirthing dan yang menerapkan hypnobirthing, serta menganalisis pengaruh hypnobirthing terhadap lama persalinan kala II di BPM Bidan Dina Garut.

\section{METODE PENELITIAN}

Penelitian merupakan quasy experiment, dengan desain posttest only with control group design, dimana terdapat dua kelompok, dengan kelompok kedua sebagai pembanding atau kelompok kontrol. Efek yang diamati pada variabel dependen dilihat dari perbedaan skor posttest antar kelompok (Salazar, Crosby, \& DiClemente, 2015). Kelompok eksperimen dalam penelitian ini dilakukan perlakuan hypnobirthing. Penelitian dilakukan di Bidan Praktik Dina Garut pada Bulan Februari sampai dengan Juni 2020.

Populasi dalam penelitian ini adalah seluruh ibu yang melahirkan di Bidan Praktik Dina Garut pada periode Februari - Juni 2020. Sampel dalam penelitian ini dipilih dengan menggunakan purposive sampling, masing-masing sejumlah 20 responden untuk kelompok eksperimen dan kelompok kontrol. Pengumpulan data dalam penelitian ini dilakukan secara observasi, dengan menggunakan lembar observasi lama persalinan kala II.

Teknik analisis yang dipergunakan dalam penelitian ini adalah uji $\mathrm{t}$ sampel independen. Sebelum dilakukan analisis data, dilakukan uji normalitas data dengan one sample KolmogorovSmirnov Test, sebagai persyaratan digunakannya statistik parametrik.

\section{HASIL DAN PEMBAHASAN \\ Analisis Univariat}

Berdasarkan hasil penelitian, karakteristik responden dapat dideskripsikan dalam tabel sebagai berikut:

Tabel 1.

Deskripsi Karakteristik Responden

\begin{tabular}{lcccccc}
\hline \multirow{2}{*}{ Karakteristik } & \multicolumn{9}{c}{ Kel. Eksperimen } & \multicolumn{2}{c}{ Kel. Kontrol } & \multirow{2}{*}{$\chi^{2}$} & \multirow{2}{*}{$\mathbf{p}$} \\
\cline { 2 - 5 } & $\mathbf{f}$ & $\%$ & $\mathbf{F}$ & $\%$ & 2,200 & 0,333 \\
\cline { 1 - 5 } Umur & 13 & 65,0 & 17 & 85,0 & & \\
a. $\quad 20-25$ tahun & 4 & 20,0 & 2 & 10,0 & & \\
b. $\quad>25-30$ tahun & 3 & 15,0 & 1 & 5,0 & & \\
c. $>30-35$ tahun & 20 & 100,0 & 20 & 100,0 & & \\
Jumlah & & & & & 4,643 & 0,098 \\
Berat Badan Lahir Bayi & 9 & 45,0 & 15 & 75,0 & & \\
a. 2500-3000 g & 9 & 45,0 & 5 & 25,0 & & \\
b. > 3000-3500 g & 2 & 10,0 & 0 & 0,0 & & \\
c. > 3500-4000 g & 20 & 100,0 & 20 & 100,0 & & \\
Jumlah & & & & &
\end{tabular}

Tabel 1 menunjukkan bahwa berdasarkan umur, responden kelompok eksperimen paling banyak berumur 20 - 25 tahun, yaitu 13 responden $(65,0 \%)$, dan paling sedikit berumur $>30-35$ tahun, yaitu 3 responden (15,0\%). Responden kelompok kontrol, paling banyak berumur 20 - 35 tahun, yaitu 17 responden $(86,0 \%)$. Berdasarkan nilai $\chi^{2}$ sebesar $2,200$ dan $p$ sebesar 0,333 ( $p>0,05)$, maka tidak ada perbedaan karakteristik umur pada kelompok eksperimen dan kelompok kontrol.

Berdasarkan berat badan lahir bayi, responden kelompok eksperimen paling banyak memiliki bayi dengan berat lahir 2500 - 3000 gram dan > 3000 - 3500 gram, masing-masing 9 responden $(45,0 \%)$. Responden kelompok kontrol, paling banyak memiliki bayi dengan berat lahir 2500 - 3000 gram, yaitu 15 responden (75,0\%). Berdasarkan nilai $\chi^{2}$ sebesar 4,643 dan $p$ sebesar $0,098$ ( $p>0,05)$, maka tidak ada perbedaan karakteristik berat badan lahir bayi pada kelompok eksperimen dan kelompok kontrol.

Lama persalinan kala II pada kelompok eksperimen dan kelompok kontrol dapat dideskripsikan dalam tabel sebagai berikut:

Tabel 2.

Deskripsi Lama Persalinan Kala II 


\begin{tabular}{lccccc}
\hline \multicolumn{1}{c}{ Lama Persalinan Kala II } & Jumlah & $\begin{array}{c}\text { Minimal } \\
\text { (Menit) }\end{array}$ & $\begin{array}{c}\text { Maksimal } \\
\text { (Menit) }\end{array}$ & $\begin{array}{c}\text { Mean } \\
\text { (Menit) }\end{array}$ & $\begin{array}{c}\text { Std. } \\
\text { Deviasi }\end{array}$ \\
\hline Kelompok Eksperimen & 20 & 15 & 25 & 20,24 & 3,0758 \\
Kelompok Kontrol & 20 & 20 & 45 & 35,75 & 7,3045 \\
\hline
\end{tabular}

Tabel 2 menunjukkan bahwa rentang lama persalinan Kala II pada kelompok eksperimen adalah $15-25$ menit dengan rata-rata sebesar 20,24 menit dan standar deviasi sebesar 3,0758. Rentang lama persalinan Kala II pada kelompok kontrol adalah 20 - 45 menit dengan rata-rata sebesar 35,75 menit dan standar deviasi sebesar 7,3045.

Analisis Bivariat
Analisis bivariat untuk mengetahui pengaruh hypnobirthing terhadap lama persalinan kala II, dilakukan dengan menggunakan uji $t$ sampel independen. Uji $t$ sampel independen merupakan statistik parametrik, sehingga sebelum dilakukan pengujian, terlebih dahulu dilakukan uji normalitas data, menggunakan uji one sample KolmogorovSmirnov. Adapun hasilnya dapat dirangkumkan dalam tabel sebagai berikut:

Tabel 3.

Hasil Pengujian Normalitas Data

\begin{tabular}{lccc}
\hline \multicolumn{1}{c}{ Variabel } & $\mathbf{Z}$ & $\mathbf{p}$ & Keterangan \\
\hline Lama Persalinan Kala II (Kelompok Eksperimen) & 0,168 & 0,143 & Normal \\
Lama Persalinan Kala II (Kelompok Kontrol) & 0,170 & 0,134 & Normal \\
\hline
\end{tabular}

Tabel 3 menunjukkan bahwa variabel lama persalinan kala II pada kelompok eksperimen maupun kelompok kontrol, berdistribusi normal, karena mempunyai nilai $p>0,5$. Berdasarkan hal ini,

maka persyaratan digunakan uji $t$ sampel independen sudah terpenuhi.

Hasil uji $t$ sampel independen pengaruh hypnobirthing terhadap lama persalinan kala II dapat dideskripsikan dalam tabel sebagai berikut:

Tabel 4.

Hasil Uji t Sampel Independen

\begin{tabular}{lcccc}
\hline \multicolumn{1}{c}{ Variabel } & N & Mean & t & p \\
\hline Lama Persalinan Kala II (Kelompok Eksperimen) & 20 & 20,24 & \multirow{2}{*}{$-8,746$} & \multirow{2}{*}{0,000} \\
Lama Persalinan Kala II (Kelompok Kontrol) & 20 & 35,75 & & \\
\hline
\end{tabular}

Tabel 4 menunjukkan bahwa nilai rata-rata lama persalinan kala II kelompok eksperimen sebesar 20,24 menit dan kelompok kontrol 35,75 menit. Nilai $t$ didapatkan sebesar $-8,746$ dengan $p$ sebesar 0,000 . Berdasarkan nilai $p<0,05$, maka disimpulkan bahwa hypnobirthing berpengaruh terhadap lama persalinan kala II. Responden yang diberikan hypnobirthing mempunyai lama persalinan kala II yang lebih cepat dibandingkan dengan yang tidak diberikan hypnobirthing.

\section{PEMBAHASAN}

Hasil penelitian didapatkan bahwa lama persalinan Kala II pada kelompok eksperimen adalah 15 - 25 menit dengan rata-rata sebesar 20,24 menit dan standar deviasi sebesar 3,0758. Rentang lama persalinan Kala II pada kelompok kontrol adalah 20 - 45 menit dengan rata-rata sebesar 35,75 menit dan standar deviasi sebesar 7,3045. Proses persalinan kala II pada primigravida biasanya berlangsung selama 2 jam dan pada multigravida biasanya berlangsung berlangsung selama 1 jam (Rini, 2010).

Responden dalam penelitian adalah ibu primigravida, dan rata-rata waktu persalinan kala II masih jauh di bawah 2 jam, sehingga persalinan kala II termasuk kategori lancar dan tidak lama, baik pada kelompok eksperimen maupun kelompok kontrol. Salah satu faktor yang berpengaruh terhadap persalinan kala II adalah usia ibu. Semua responden penelitian berusia 20 - 35 tahun, sehingga aman untuk melahirkan. Pada usia ini, maka perkembangan alat-alat reproduksi sudah matang, sudah siap untuk kehamilan dan proses persalinan. Hal ini mengurangi terjadinya komplikasi dalam persalinan, sehingga persalinan dalam dilakukan lebih cepat. Penelitian terdahulu juga telah membuktikan pengaruh usia ibu terhadap lama persalinan (Ardhiyanti \& Susanti, 2016). 
Hasil penelitian menunjukkan bahwa hypnobirthing berpengaruh terhadap lama persalinan kala II. Pemberian hypnobirthing terbukti mampu untuk mempercepat lama persalinan kala II. Apabila melihat hasil penelitian terlihat bahwa beda rata-rata lama persalinan kala II pada kelompok eksperimen dan kelompok kontrol, terlihat bahwa hypnobirthing mampu untuk mempercepat 15,5 menit persalinan kala II. Hasil penelitian ini mendukung hasil penelitian terdahulu (Rini, 2010). Penelitian terdahulu juga membuktikan bahwa Pemberian hypnobirthing terbukti mampu untuk mempercepat lama persalinan kala I (Widiawati, 2019); (Devi, Sulastriningsih, \& Tiawaningrum, 2018); (Karuniawati \& Fauziandari, 2017); (Nuryanti, Nisman, \& Siswosudarmo, 2017); (Astuti \& Noviyanti, 2015).

Respon stres menjadi faktor yang menempati urutan paling atas sebagai salah satu faktor penyebab persalinan lama (Wildan, Jamhariyah, \& Purwaningrum, 2013). Faktor lain yang berpengaruh terhadap persalinan lama adalah kondisi psikologis ibu melahirkan, yaitu persepsi ibu pada rasa nyeri serta tingkat kecemasan pada saat persalinan. Persepsi terhadap nyeri yang berlebihan berdampak pada respon psikologis, sehingga menurunkan tingkat kontraksi rahim, dan hal ini berakibat pada persalinan yang lama (Astuti \& Noviyanti, 2015).

Hypnobirthing merupakan salah satu upaya nonfarmakologi untuk mengantisipasi adanya stres, respon pada nyeri dan kecemasan yang berlebihan pada ibu saat menjalani proses persalinan. Penelitian terdahulu yang dilakukan telah membuktikan bahwa hypnobirthing mampu untuk menurunkan nyeri pada persalinan (Legiati \& Widiawati, 2017); (Astuti \& Noviyanti, 2015), dan juga menurunkan kecemasan menjalani persalinan (Sariati, Windari, \& Hastuti, 2016). Kecemasan saat persalinan menyebabkan pembuluh-pembuluh arteri yang mengarah ke rahim berkontraksi dan menegang, sehingga menimbulkan rasa sakit. Ketika rasa cemas hilang maka otot-otot akan melemas dan melentur, serviks dapat menipis serta membuka secara alami dan mendorong bayi dengan mudah sehingga persalinan berlangsung lancar dan lebih cepat dengan rasa sakit yang minimal. Hypnobirthing melalui teknik relaksasi dapat menghilangkan kecemasan saat persalinan sehingga memberikan sugesti positif kepada ibu melahirkan bahwa proses persalinan itu nikmat. Hal ini menyebabkan ibu melahirkan akan merasa rileks dan nyaman, sehingga masa persalinan dilakukan dengan tenang. Kondisi rileks berpengaruh terhadap alam bawah sadar, mengatur keselarasan tubuh dan kemudian otak akan mengalirkan hormon endorfin yang berfungsi sebagai anestesi atau pembiusan yang alami, sehingga mengurangi rasa sakit dan memberikan rasa nyaman, dan menghilangkan kecemasan ibu. Hal ini memberikan kelancaran pada proses persalinan sehingga berlangsung lebih cepat.

\section{KESIMPULAN}

Hasil penelitian didapatkan bahwa lama persalinan Kala II pada kelompok eksperimen adalah $15-25$ menit dengan rata-rata sebesar 20,24 menit dan standar deviasi sebesar 3,0758. Rentang lama persalinan Kala II pada kelompok kontrol adalah 20 -45 menit dengan rata-rata sebesar 35,75 menit dan standar deviasi sebesar 7,3045.

Hypnobirthing berpengaruh terhadap lama persalinan kala II. Pemberian hypnobirthing terbukti mampu untuk mempercepat lama persalinan kala II. Apabila melihat hasil penelitian terlihat bahwa beda rata-rata lama persalinan kala II pada kelompok eksperimen dan kelompok kontrol, terlihat bahwa hypnobirthing mampu untuk mempercepat 15,5 menit persalinan kala II.

\section{SARAN}

Apabila melihat hasil penelitian di atas, maka hendaknya Bidan Praktik Dina khususnya dan secara umum seluruh bidan yang ada di wilayah Garut, agar dapat menerapkan kepada seluruh ibu hamil mengenai hypnobirthing dengan biaya yang terjangkau, dan menerapkan pada seluruh proses persalinan. Selain itu, hendaknya bidan juga membimbing ibu dalam proses hypnobirthing pada saat persalinan. Apabila memungkinkan hendaknya dapat membuat suatu SOP persalinan dengan memasukkan hypnobirthing dalam prosedur penatalaksanaan persalinan.

\section{DAFTAR PUSTAKA}

Ardhiyanti, Y., \& Susanti, S. (2016). Faktor lbu yang Berhubungan dengan Kejadian Persalinan Lama di RSUD Arifin Achmad Pekanbaru. Jurnal Kesehatan Komunitas, 3(2), 83-87.

Astuti, I., \& Noviyanti, N. (2015). Pengaruh Hypnobirthing Terhadap Tingkat Nyeri dan Kemajuan Persalinan Pada Ibu Bersalin di BPM Kota Cimahi. SEAJOM: The Southeast Asia Journal of Midwifery, 1(1), 43-47.

Devi, T. E. R., Sulastriningsih, K., \& Tiawaningrum, E. (2018). Pengaruh Yoga Prenatal dan Hypnobirthing terhadap Proses Persalinan Kala I pada Ibu Bersalin di BPM Restu Depok Periode Januari-Juni Tahun 2017. Jurnal Bidan, 4(1), 26-32. 
Karuniawati, B., \& Fauziandari, E. N. (2017). Hypnobirthing Terhadap Lama Persalinan Kala I. Jurnal Kesehatan Samodra IImu, 8(2), 110-116.

Legiati, T., \& Widiawati, I. (2017). Hypnobirthing Effect on the Level of Pain in Labor. KEMAS: Jurnal Kesehatan Masyarakat, 13(2), 185190.

Nuryanti, Y., Nisman, W. A., \& Siswosudarmo, R. (2017). Manfaat Latihan Relaksasi Hypnobirthing Pada Proses Persalinan Kala I. Jurnal Persatuan Perawat Nasional Indonesia (JPPNI), 1(3), 200-206.

Prawirohardjo, S. (2010). Buku Acuan Nasional Pelayanan Kesehatan Maternal dan Neonatal. Jakarta : PT Bina Pustaka Sarwono Prawirohardjo.

Rini, S. (2010). Pengaruh Hypnobirthing Terhadap Percepatan Lama Kala II Persalinan di Puskesmas Kota Yogyakarta Tahun 2010. Viva Medika, 3(5), 25-32.
Salazar, L. F., Crosby, R. A., \& DiClemente, R.J. (2015). Research Methods in Health Promotion. San Francisco: Jossey-Bass.

Sariati, Y., Windari, E. N., \& Hastuti, N. A. R. (2016). Pengaruh Hypnobirthing terhadap Tingkat Kecemasan Ibu Bersalin dan Lama Persalinan. Jurnal IImiah Bidan, 1(3), 35-44.

Syahda, S., \& Ramaida, R. (2017). Pengaruh Hypnobirthing Terhadap Kala I Pada Ibu Bersalin di Klinik Pratama Mulia Medica Desa Sungai Buluh Kecamatan Singingi Hilir Kabupaten Kuantan Singingi Tahun 2015. Jurnal Endurance, 2(2), 151-157.

Widiawati, I. (2019). Melahirkan Nyaman dan Cepat dengan Hypnobirthing. Care: Jurnal IImiah IImu Kesehatan, 7(1), 45-52.

Wildan, M., Jamhariyah, \& Purwaningrum, Y. (2013). Pengaruh Teknik Relaksasi Terhadap Adaptasi Nyeri Persalinan Ibu Bersalin Kala I Fase Aktif di BPS Wilayah Puskesmas Patrang Kabupaten Jember Tahun 2012. IKESMA, 9(1), 65-73. 